\title{
Albas y alboradas en el cancionero tradicional mexicano: herencia y cambio
}

\author{
MARIANA MASERA \\ UNAM, México
}

En la tradición oral existen dos grandes tendencias; la conservación y la variación. Los textos que se han preservado en el tiempo son manifestaciones de la primera, en tanto que las divergencias regionales de los cantares - tanto sincrónicas como diacrónicas- muestran la fuerza de la segunda. A veces las diferencias entre los textos son tales que se puede hablar de un estilo distinto, de una "escuela popular" ${ }^{1}$.

La poesía tradicional se trasmite principalmente de manera oral y el individuo participa tanto en la creación como en la recreación del texto. Ello da como resultado que un mismo cantar pueda tener diferentes realizaciones; de acuerdo con Menéndez Pidal ${ }^{2}$ :

Esta poesía que se rehace en cada repetición, que se refunde en cada una de sus variantes, las cuales viven y se propagan en ondas de carácter colectivo a través de un grupo humano y sobre un territorio determinado, es la poesía propiamente tradicional [...] La esencia de lo tradicional está pues más allá de la mera recepción o aceptación de una poesía por el pueblo [...]: está en la reelaboración de la poesía por medio de las variantes.

Otro rasgo diferenciador de la poesía popular es la escasez de los recursos expresivos que tanto el creador y recreador como el que escucha deben conocer. De hecho, la estética colectiva es la que se impone al individuo en cada realización ${ }^{3}$.

La comunidad de medios expresivos en la poesía popular hace imprescindible el estudio de los lugares comunes, entre éstos últimos se

\footnotetext{
1 Veáse el ya clásico artículo del erudito Sergio BALDI, "Sul concetto di poesia popolare», Leonardo: Rassegna Bibliografica, 15 (1946), pp. 1-21 y 65-77, p. 66.

2 Ramón MenÉNDez PIDAL, El Romancero: Teoría e investigaciones de Menéndez Pidal (Biblioteca de ensayos, 3) (Madrid: Paez, s.a), pp. 39-40.

3 En este trabajo uso como equivalentes los términos poesía tradicional, poesía popular y poesía oral.
} 
destacan los motivos entendidos como "temas menores que se estereotipan en cuanto a su modo de experiencia, pero conservan su frescura y agiliciad en cuanto a su modo de expresión" ${ }^{4}$.

Habría que añadir a esta definición que, debido a la apertura de las estructuras de la poesía popular, los motivos no sólo se pueden considerar como unidades recurrentes, sino también como unidades de significación ${ }^{5}$. Lo anterior explica que a pesar de la existencia de una variabilidad a nivel superficial del motivo, éste conserve su significado a nivel profundo.

Mencionar que existen coincidencias entre la poesía popular mexicana y la antigua lírica popular medieval, no es nuevo, como ha sido demostrado ya por algunos estudiosos a través de las coincidencias textuales y la comunidad de medios expresivos entre las coplas antiguas y modernas. Baste citar algunos de los trabajos más conocidos, como los de Vicente T. Mendoza, Carlos Magis, Yvette Jiménez de Báez y Margit Frenk ${ }^{6}$. A pesar de ello no se han cubierto aún de manera sistemática los encuentros y desencuentros entre los dos cancioneros.

El presente trabajo sobre el cambio y la preservación del motivo de "el alba erótica" en el cancionero mexicano no pretende ser exhaustivo, sino una cala donde se observe la originalidad de la expresión tradicional mexicana frente al cancionero peninsular ${ }^{7}$.

4 Veáse Carlos H. MAGis, La lírica popular contemporánea (México: El Colegio de México, 1969), p. 29.

5 Veáse el artículo de Aurelio GonZález, "Los motivos como unidad de significación en la lírica tradicional", Mariana MASERA et al. (ed.), Tradición Oral y folklore en la lírica bispánica, II: Temas y motivos; teoria; oralidad (Londres: Papers of the Medieval Hispanic Research Seminar, en prensa).

6 Los trabajos a los que me refiero son Vicente T. MENDOZA, La canción Mexicana. Ensayo de clasificación y Antología. Serie de Estudios, 1. (México; UNAM, Instituto de Investigaciones Estéticas, 1961); Horacio MAGIS, op. cit., el trabajo que dedicó a las relaciones entre la lírica popular y la culta; Yvette JIMÉNEZ DE BÁEZ, Lírica cortesana y lírica popular actual, Jornadas, 64 (México: El Colegio de México, 1969); los trabajos de Margit FrENK et al., Cancionero folklórico de México (México: El Colegio de México, 1975-85), 5 vols.; y el Corpus de la antigua lírica popular hispánica (siglos XV a XVII), Nueva Biblioteca de Erudición y Crítica, I (Madrid: Castalia, 1987).

7 La investigación se realizó tomando en cuenta todas las canciones en las que el motivo de el alba, amanecer o madrugada se asociaran con el encuentro o despedida de los amantes. Los textos contemporáneos pertenecen al Cancionero Folklórico de México, al que de ahora en adelante denominaré CFM. Las canciones han conservado el número de la antología. Todas las canciones antiguas pertenecen a la antología Corpus de la antigua lírica popular (siglos XV-XVI) de Margit Frenk, que se abreviará como $C$. También se preserva la numeración de los textos dada en la obra. 


\section{EL ALBA}

El alba erótica es uno de los motivos que comparte la lírica popular medieval hispánica con otras tradiciones. Expresa el momento en que los amantes se despiden después de una noche de amor (albas), o en el que los amantes se encuentran al amanecer (alboradas).

Su origen es una cuestión polémica entre los estudiosos, dada su universalidad y antigüedad ${ }^{8}$. Entre los rasgos que se han destacado está la posible relación del alba con las festividades paganas asociadas a los ritos de primavera 9. Además, el monólogo de voz femenina y el canto de las aves fueron considerados como componentes esenciales de este motivo por Alfred Jeanroy ${ }^{10}$.

En el antiguo cancionero popular hispánico existen pocas canciones donde los amantes se despiden al amanecer después del encuentro amoroso, por el contrario, existe una mayor recurrencia de coplas donde la mujer cita a su amado al albor. Véanse los siguientes ejemplos:

$$
\begin{aligned}
& \text { Ora vete, amor, y bete, } \\
& \text { cata que amanesçe. }(C 454 a)^{11}
\end{aligned}
$$

8 En cuanto a los orígenes populares y aristocráticos del alba consúltese entre otros: Las jarchas mozárabes y los comienzos de la lírica hispánica (México: El Colegio de México 1971; reimpr. 1985), pp. 88-89. El alba en la lírica tradicional hispánica también fue estudiada, entre otros, por: José María Alín, El cancionero español de tipo tradicional (Madrid: Taurus, 1968), pp. 164-66; Antonio SÁNCHEZ ROMERALO, El villancico: estudios sobre la lírica popular en los siglos $X V$ y XVI, Estudios y Ensayos, II (Madrid: Gredos, 1969), p. 63; Margit FRENK, Entre folklore y literatura: lírica bispánica antigua (México: El Colegio de México, 1971), p. 68 y Johnn G. Cummins, The Spanish Traditional Lyric (Oxford: Pergamon Press, 1977), pp. 57-60. Además véase mi estudio sobre el simbolismo del alba en la antigua lírica hispánica y el cancionero peninsular actual, Symbolism and Some Other Aspects of Traditional Hispanic Lyrics: A Comparative Study of Late Medieval Lyric and Modern Popular Song (Tesis Doctoral: Queen Mary and Westfield College, University of London, 1995), pp. 28-41.

9 Uno de los grandes estudios dedicados al alba de un gran número de países es el de Arthur T. HATTO (ed.), Eos: An Enquiry into the Thenze of Lovers' Meetings and Partings at Dawn in Poetry (The Hague: Mouton, 1965). El enfoque multiliterario permite establecer correlaciones muy iluminadoras.

10 Alfred Jeanroy, Les Origines de la poésie lyrique en France au Moyen Âge (Paris: Honoré Champion, 1904, 2." ed.), pp. 64-141.

11 En las canciones españolas contemporáneas se encuentran supervivencias de estas canciones como: "Levántate luego, / dulce amor, y vete, / que ya el gallo canta y el día amanece" (Maximiano TrAPERo, ed., Lírica tradicional canaria, Biblioteca Clásica Canaria, 3 [Islas Canarias: Viceconsejería de Cultura y Deporte, Gobierno de Canarias, 1990], p. 76). 
$\mathrm{Al}$ alva venid, buen amigo, al alva venid. $(C 452)^{12}$

Las alboradas describen el momento de la reunión de los amantes cuando la niña realiza alguna labor cotidiana como lavar la ropa en el río o ir a buscar agua. Frecuentemente la muchacha culpa a su madre de que haya sucedido el encuentro amoroso para justificar su comportamiento. Los pretextos de la joven enamorada se repiten continuamente dejando entrever en la explicación el hecho que oculta: las "excusas transparentes" en términos de John Gornall ${ }^{13}$.

Envíame mi madre

por agua a la fonte frida:

vengo del amor ferida. (C 317)

La naturaleza entera forma parte de la escena erótica, es partícipe del encuentro amoroso, auspiciándolo y cargándolo de una sensualidad profunda. Los símbolos elementales son identificados con la sexualidad de la niña ${ }^{14}$ :

\author{
Levantéme, ¡o, madre! \\ mañanica frida, \\ fuy a cortar la rosa \\ la rosa florida. \\ Malo es de guardar.
}

12 En los estribillos antiguos la mujer invita a la hermana al amanecer:

Vente a la mañana, hermana,

vente a la mañana. (C 451)

El fragmento de la canción parece estar relacionado con los ritos donde se guarda una flor debajo de la cama o almohada y se espera hasta el otro día para ver si florece. Si florea es un signo de que su amor sería correspondido. Este rito propiciatorio se relaciona con el día de San Juan (José Manuel PEDrosA, "La flor en la cama: simbolismo y ritual de un epitalamio sefardí en Marruecos", "Quien bubiese tal ventura": Medieval Hispanic Studies in Honour of Alan Deyermond [Londres: Department of Hispanic Studies, Queen Mary and Westfield College, 1997], pp. 379-386).

13 Me refiero al artículo "Transparent Excuses in Spanish Traditional Lyric: A Motif Overlooked", MLN, 103 (1988), pp. 436-439. Baste mencionar que las excusas femeninas más comunes con el motivo del alba son siempre asociadas a las labores cotidianas femeninas. La primera manifestación registrada de este motivo en la Península es en la tradición hispánico-portuguesa, en las cantigas de amigo.

14 La importancia del simbolismo de la naturaleza en la lírica tradicional europea ha sido comentada por Margit FRENK quien afirma que in European folk songs, probably no aspect of natural life ever appears in its literal sense only" (Symbolism in Old Spanish Folk Songs, The Kate Elder Lecture, 4 [London: Dept of Hispanic Studies, Queen Mary and Westfield Collegel, p. 4). 


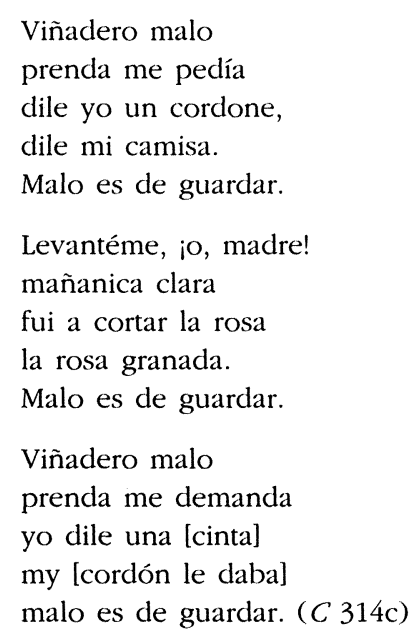

En esta sencilla escena se encuentran algunos de los motivos eróticos más frecuentes asociados al alba: la niña que va a cortar la rosa, la entrega de prendas personales - la cinta y el cordón- y el guardián de la viña. Todos ellos, sumados a la constante repetición del último verso del refrán que encabeza el cantar "Niña y viña, peral y havar / malo es de guardar, revelan el encuentro amoroso de los amantes e intensifican el erotismo de la escena. Además la frecuente asociación de los mismos motivos en la lírica antigua y la supervivencia de esta aglutinación en el cancionero hispánico contemporáneo sugieren la existencia de símbolos principales alrededor de los cuales gravitan otros como también ha señalado Paula Olinger, sin llegar a la fijación de ellos ${ }^{15}$.

Por otra parte, el motivo del alba erótica se conserva en la poesía tradicional mexicana; no obstante, en contraste con la antigua lírica hispá-

15 Véase Paula OLINGER, Images of Transformation in Traditional Hispanic Poetry (Newark, DE: Juan de la Cuesta), p. 11; y MASERA, Symbolism..., op. cit. Pierre Bec estudia la existencia de una estereotipación de motivos en el exordio a la canción popularizante francesa desde la Edad Media hasta ahora. Algunos de esos motivos también existen en la canción tradicional conservando su significado erótico: "nous voulons tenter ici l'étude. [...] de trois motifs utilisés à maintes reprises, aussi bien dans l'éxorde médieval que dans ce lui de la chanson traditionelle et, dans le deux cas, dans un contexte à multiples variantes mais presque toujours résolument érotique [...] Ces trois motifs réduits à leur typisation minimale sont: 1) le lever matinal, 2) l'éntrée au verger, 3) la cueillette des fleures". Pierre BEC, "L'Accés au lieu érotique: motifs et exorde dans la lyrique popularisante du Moyen Âge a nos jours", Willy VAN HOECKE y Welken HUYSEN (eds.), Love and Marriage in the Twelfth Century (Leuven: University Press, 1981), pp. 250-299. El estudio de Bec confirma cómo se preserva el erotismo y la reutilización de los motivos, hecho que también se da en el cancionero hispánico y portugués. 
nica, la voz femenina ha quedado disminuida a una minoría de canciones. Esta disminución no es un fenómeno original de las canciones de México, sino que es común a los cancioneros contemporáneos en español y portugués ${ }^{16}$.

El cambio de perspectiva ha sido interpretado por algunos autores como una de las influencias de la lírica culta sobre la poesía popular. Se debería añadir a esta discusión la voz masculina de otras tradiciones europeas, ya que la reducción de la voz femenina también ocurre en otros cancioneros donde la convivencia entre lírica culta y popular durante los siglos XV, XVI y xvil difiere de la española, como en el caso de los ritornellos toscanos ${ }^{17}$.

El amor sigue siendo el tema principal del cancionero mexicano y es la voz masculina la que ha tomado la iniciativa erótica

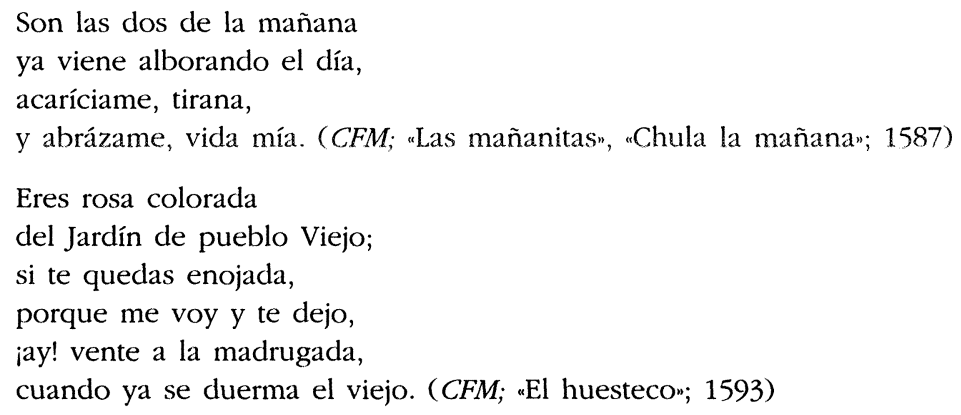

En las primeras cuatro líneas del cantar precedente es claro que la voz es masculina, en tanto que en el último dístico no. Por un lado podría estar en boca de mujer, pues ella es quien en la mayoría de los casos invita al hombre a su espacio ${ }^{18}$.

16 La importancia de la voz femenina en el cancionero antiguo queda muy clara en palabras de Margit FRENK: "Entre la lírica popular hispánica de la Edad Media y la poesía aristocrática contemporánea el rasgo diferenciador más notable y asombroso es, sin duda, la presencia en la primera, de la voz femenina [...] Esa voz de mujer se contrapone a la voz de hombre que monopoliza la lírica cortesana paneuropea ("Sobre las canciones femeninas de la Edad Media española", Medievalia [1990] 5, pp. xv-XIX; p. xv) y Margit FRENK, "Transculturación de la voz femenina en la lírica renacentista", en Augustin REDONDO (coord.), Image de la femme en Espagne au Xvème-XVIIème siècles. Des traditions aux renouvellements et aux émergences d'image nouvelle (Paris: Publications de la Sorbonne), pp. 91-102.

17 Veáse para el cambio de voz Margit FrENK, "La canción popular femenina en el Siglo de Oron, en Alan Deyermond y Ralph Penny (eds.), Actas del Primer Congreso Anglo-Hispano, II: Literatura (Madrid: Castalia, 1993), pp. 139-59.

18 Además no se puede dejar de mencionar que estos versos recuerdan al antiguo cantar "Vente a la mañana, hermana" que, dada la evidencia de Pedrosa (op. cit.), podría ser un "cantar de hermana". y tener voz femenina (ver nota 5). 
En la siguiente composición, donde no existe una marca textual de la voz como masculina o femenina, el amante señala el comienzo y final del encuentro amoroso: la medianoche y el amanecer.

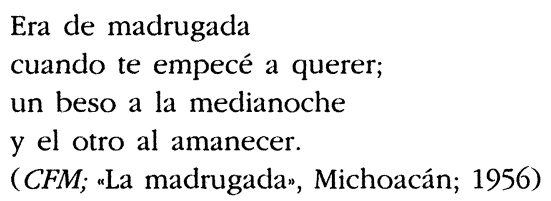

De acuerdo con los ejemplos, las alboradas son comunes en el cancionero mexicano. Sin embargo no se puede decir lo mismo de las albas, ya que difiere según la voz de la canción. En algunos cantares de voz masculina, a pesar de que las señales como la luz del día y el canto del gallo anuncien la partida, la mención hecha por el locutor que viene a despedirse, sugiere una situación ambigua. Por un lado, se preserva la iniciativa erótica del hombre y la atmósfera sensual. Por otro, el motivo se ha contaminado con la despedida del amante antes de irse al trabajo, que se puede ubicar en las tradicionales mañanitas (véase nota 24).

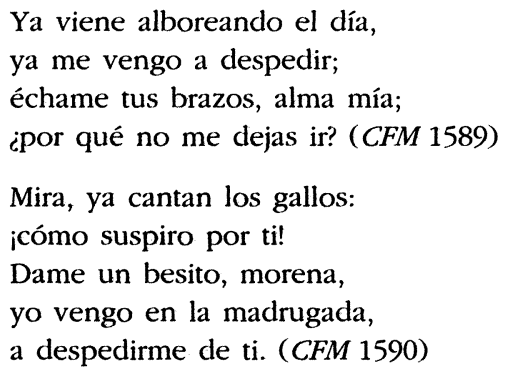

El canto del gallo que anuncia la madrugada es otro elemento común con el cancionero viejo. De hecho, este motivo distingue a los antiguos estribillos españoles de otras tradiciones, ya que lo más común es que sea el canto de las aves el que anuncie el amanecer y, como consecuencia, la separación de los amantes. Veamos en los antiguos cantares:

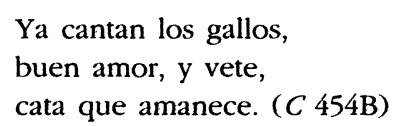

El canto del gallo no es exclusivo de la poesía oral ya que es un motivo universal, presente tanto en literatura profana como religiosa ${ }^{19}$. El

19 Para el canto del gallo como símbolo erótico en los antiguos estribillos véase M. MASERA, Symbolism, pp. 32-39. De hecho ya en Sebastián de Covarrubias el canto 
poder evocador y la fuerza de la imagen se refleja en su preservación en los cancioneros contemporáneos portugués, gallego y canario.

Los dos elementos esenciales del alba - la separación de los amantes y el canto de gallo- concurren también en una copla dialogada del cancionero mexicano. La vOz masculina se percata de que es tiempo de partir, mientras que la vOZ femenina exige al amante que se quede hasta el amanecer. A esto se añade que el amante es moreno:

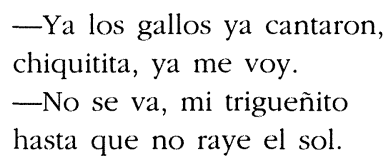

Nuevamente la voz femenina demanda y casi ordena al amante que debe pasar la noche con ella y, quizás también ordenándole, su partida a la mañana siguiente:

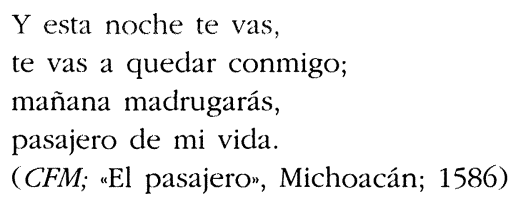

En los últimos dos ejemplos se ha visto cómo la voz femenina ordena, exige y demanda al hombre que permanezca a su lado. Hecho que contrasta con el cancionero antiguo donde la voz pone de sobreaviso al amante. A pesar de la diferencia en cuanto a la orden, sí existe una comunidad en la expresión de los deseos sensuales de la mujer en ambos cancioneros. El escaso número de cantares de voz femenina con este motivo no permite sacar conclusiones decisivas. Lo que quizás sí se puede decir es que no existe una diferencia esencial en el lenguaje del deseo entre la voz masculina y la femenina en el cancionero mexicano ${ }^{20}$.

del gallo es considerado un símbolo erótico (Sebastián de Covarrubias, Tesoro de la lengua castellana, ed. Martín de Riquer [Barcelona: Horta, 1943]: sv. gallo). Veáse para el gallo en composiciones religiosas: HATTO, Eos, pp. 87-96, Jane HAwKING, The Dawn: A Study of the Image and Related Themes in the Traditional Love Lyric of Medieval Spain and Portugal (Tesis Doctoral: Westfield College, University of London, 1979), p. 74. En cuanto al simbolismo del gallo en general se pueden consultar los trabajos de Arthur T. HATTO, Eos, 787-792; asimismo la explicación dada por Jean Chevalier y Alain GHEERBrant, Dictionnaire des symboles, mythes, reves, coutumes, gestes, formes, figures, couleurs, nombres (Paris: Robert Laffont/Jupiter; 1982; reimpr. 1996), s.v. Coq; y para la tradición inglesa véase el diccionario de supersticiones de Iona OPIE y Moira TATEM, A Dictionnary of Superstitions (Oxford: University Press, 1992), s.v. cock.

20 En los antiguos estribillos españoles la presencia de la voz femenina y masculina es equiparable (Véase Mariana MASERA, “La voz femenina en la antigua lírica popular 
El alba es descrita como la hora sensual desde el punto de vista de un amante celoso, quien se queja de que su amada le haya negado la oportunidad de estar juntos con cierto temor de que podría estar siendo engañado:

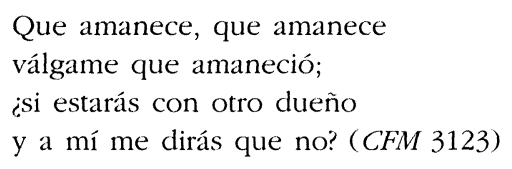

Llama la atención el hecho de que aquí se hayan invertido los roles habituales en el motivo tradicional, donde la tardanza del hombre despierta los celos en la mujer. En la lírica popular antigua frecuentemente una voz femenina lamenta la ausencia del amado. Baste recordar la copla que canta Melibea en la Celestina:

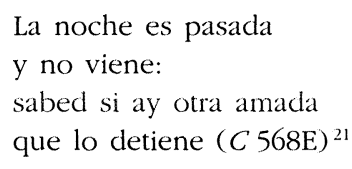

Hasta aquí hemos visto varios ejemplos de cómo se ha producido un cambio de voz de femenina a masculina y como consecuencia una inversión de los roles tradicionales, ya que en vez de ser la mujer $-\mathrm{y}$ me refiero a los cantares en boca de mujer del antiguo cancionero popularquien tome el papel del hombre, en el cancionero mexicano es el hombre quien toma el rol de la mujer. Todo ello me lleva a pensar que aunque la voz masculina en un primer momento haya sido fruto de la convivencia con la lírica cortés, la manera directa y apasionada de expresarse indica que la voz ya ha sido permeada por la voz femenina de la lírica popular. De manera que la voz masculina ha incorporado los motivos de la voz femenina y casi ha eliminado a ésta.

En otras coplas el alba ya no es el momento del encuentro de los amantes y se convierte en la hora más propicia para contemplar a la amada o al amado. A pesar de ello, se contagia aún del erotismo:

hispánican [Tesis de Licenciatura: Universidad Nacional Autónoma de México), 1991], p. 115). Sobre la voz masculina en la canción tradicional véanse: Fernando CABO ASEGUINOLAZA, "Sobre la perspectiva masculina en la lírica tradicional castellana", Vicente Beltrán (ed.), Actas del I Congreso de la Asociación Hispánica de Literatura Medieval Santiago de Compostela, 2 al 6 de diciembre de 1985 (Barcelona: PPU, 1988), pp. 22530, y mi trabajo, "Fue a la ciudad mi morena / si me querrá cuando vuelva", La voz masculina en la antigua lírica tradicional, VII Jornadas Medievales, 1998 (en prensa).

21 Otros estribillos en el $C$ donde la mujer manifiesta sus celos son: 291, $568 \mathrm{~A}$, B, C, D. 
¡Ay, cuán bonito es tener

amor en la vecindad!

Todos los días que amanece,

mirar y mirar allá. (CFM 4526a) ${ }^{22}$

El despertar de la naturaleza y de la mujer hermosa también se relacionan con el alba en otras coplas, donde en vez de producirse el encuentro amoroso, el hombre saluda al día y a su amada. Los cantares se encuentran dentro del género de "las mañanitas" que son canciones de saludo a la madrugada, ya sean religiosas o profanas:

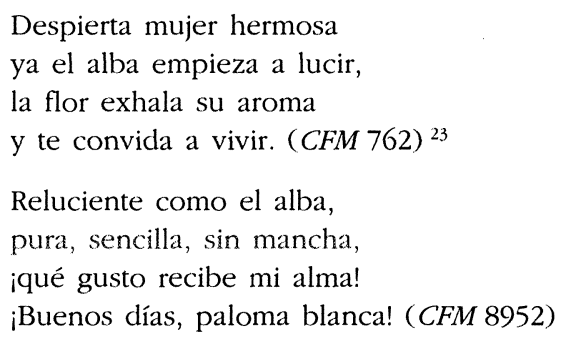

El ámbito erótico del alba no sólo se ciñe a describir el despertar de la mujer hermosa, en otras ocasiones el cortar la flor al amanecer y la belleza de la mujer se convierten en un sólo motivo en el cancionero mexicano (las cursivas son mías) ${ }^{24}$ :

22 En algunas canciones, el amante va a buscar a la mujer pero parece no hallarla en esta copla menos afortunada:

Ándale y ándale, que amanece,

cuando la busco, ya no parece;

ándale y ándale, corre pronto,

porque no digan que soy tan tonto. (CFM 3579)

23 Saludar a la amada en la mañana es un rasgo muy común en las serenatas del cancionero popular de la península ibérica: "Esta mañanita, yo te desperté / porque ya es de día / porque ya se ve, / porque es la hora del amanecer / de venirte a ver" (Sixto CóRdova Y OÑA, ed., Cancionero popular de la provincia de Santander [Santander: Diputación Provincial, 1980], II, 216, num. 36). Existe otra canción en el cancionero cuyo género de voz no es sencillo determinar y que anoto aquí:

Abra ya sus ventanitas,

que viene alborando el día

cantando estas mañanitas me iré,

comadrita mía. (CFM 7479)

24 En otras coplas, la unidad entre el plano real y el imaginario parecería llevar al oyente a una interpretación literal: "La rosa pa que sea buena / se corta de mañanita, mayormente la azucena, / que es una flor exquisita: / en la noche se serena, / viene el sol y la marchita". (CFM 596, "La azucena"). 


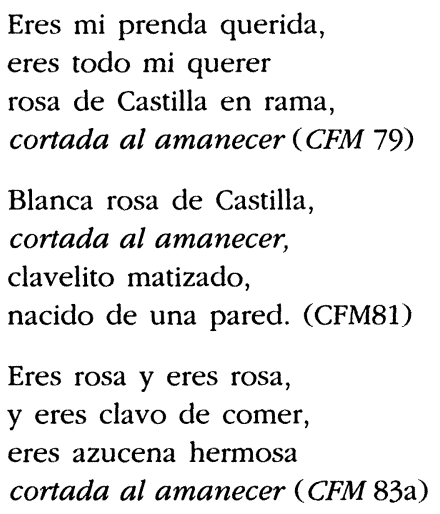

Dentro de este grupo se podría incluir aquella canción que describe el olor de la amada como una flor que exhala su aroma al amanecer. El identificar a la mujer con una flor perfumada también es una imagen que proviene de antaño ${ }^{25}$ :

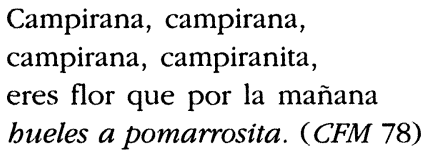

En los textos es evidente la similitud de las imágenes con las del cantar antiguo "Levantéme, jo, madre! / mañanica frida.. El significado de la pérdida de la virginidad de la mujer y del encuentro amoroso parecen condensarse, aún más, hasta concentrarse solamente en la belleza de la mujer. Esta plurivalencia semántica es característica de los símbolos de la tradición oral.

El canto de los pájaros al despertar el día se transforma en la imagen de la belleza de la amada, quien es identificada con la paloma. La identificación de la mujer con un ave se remonta al cancionero antiguo, aunque la frecuencia de esta imagen en el cancionero contemporáneo es mucho mayor y se ha convertido en un cliché:

25 Véase para el perfume de la flor como símbolo erótico en el cancionero hispánico MASERA, Symbolism, pp. 224-226. Además vale la pena recordar una de las excusas ofrecidas por Gerineldo en una versión portuguesa:

¿Dónde vienes, Gerinaldo,

con color tan desvaído?

Una flor de las más fuertes me puso descolorido.

Véase Fermín BOUZA BREY, Etnografía y folklore de Galicia, ed. José Luis Bouza Álvarez (Vigo: Xerais, 1982), p. 145. 
Eres mi prenda querida de todito mi querer eres aquella paloma que canta al amanecer ( $C F M$ 95)

Como hemos visto, la hermosura de la mujer se puede identificar con diferentes elementos eróticos, siempre tomados de la naturaleza, asociados al alba: la flor cortada, el perfume y las aves que cantan al amanecer. El cambio de asociaciones, como mencioné antes, muestra cómo en un motivo de la poesía oral los símbolos pueden tener varios significados.

Existe otra serie de coplas donde el alba se identifica con el despertar de la naturaleza y el momento del amor. Ahora, visto desde la perspectiva del amante adolorido.

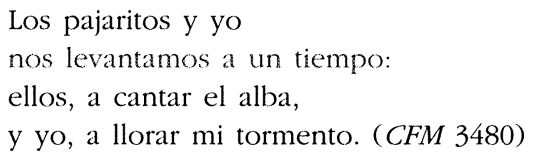

El sufrimiento del amante que contrasta con la hermosura y alegría de la naturaleza remite a los motivos de la lírica cortés, donde se canta al amor frustrado y doloroso (más que al amor realizado como en el cancionero antiguo hispánico) en el marco de la naturaleza que invita al amor; como en estos ejemplos del cancionero mexicano ${ }^{26}$ :

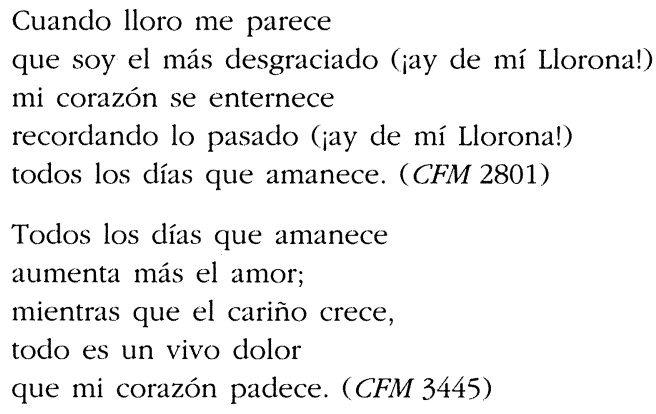

26 El contraste entre la celebración de la naturaleza y la tristeza del amante aparece en la cantiga de amigo de Nunes de Torneol: "Levad amigo que dormides as manãhas frias". José Joaquim NunEs (ed.), Cantigas d'amigo dos trovadores galego portugueses (Coimbra: Imprensa da Universidade, 1926-1928), 3 vols, núm. 75. Véase el trabajo de Vincen Beltrán, "A alba de Nuno Fernandez", Revista Galega do Ensino, 17 (1997), pp. 89-109, donde concluye que: “En definitiva, atopámonos diante do lamento da protagonista por un amor roto, probablemente, diante do desexo —quizais máis poético ca verosímil- da reuni-los lazos que o amigo rompeun. 
El contraste entre la naturaleza y el estado de ánimo del amante tiene antecedentes en las cantigas de amigo en la conocida "Levad, amigo que dormides as manhâs frias", empero quien se queja de su suerte es una mujer. Nuevamente se observa en el cancionero mexicano un cambio de $\mathrm{VOZ}^{27}$.

La alegría y hermosura de la naturaleza al comenzar el día aparecen en otras coplas, donde ya no se asocian a la escena erótica del encuentro de los amantes, sino al festejo de la llegada del amanecer, como en los antiguos cantares españoles:

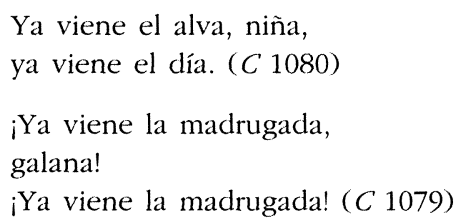

En el cancionero popular mexicano cuando se celebra la naturaleza al llegar la mañana, se suelen agregar otros motivos, como el canto de los pájaros que anuncian el alba, los verdes árboles y las sierras altas. Todos ellos motivos eróticos en el cancionero antiguo ${ }^{28}$ :

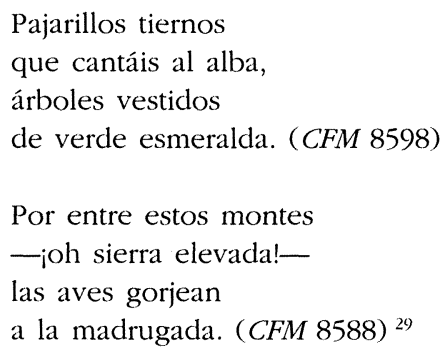

Una particularidad del cancionero popular hispánico es su estrecha relación con el mundo religioso, que se observa en la gran cantidad de coplas amorosas vueltas a lo divino y en el uso de los mismos motivos

27 Para Firminho CRESPO, "Temas trovadorescos e populares", Occidente, 68 (1965), pp. 61-65, ésta es la única cantiga que se puede asociar con el género de alba.

28 El canto de los pájaros a la madrugada también se convierte en equivalente de belleza de la mujer amada: "Eres mi prenda querida, / eres mi prenda adorada, / eres aquella paloma / que canta a la madrugada" (CFM 92). (Las cursivas son mías).

29 Las sierras altas y los montes se han identificado como lugar de encuentro de los amantes en los antiguos estribillos. Estos motivos los he estudiado con detenimiento en otra parte (MASERA, Symbolism, pp. 228-239). 
eróticos tanto en coplas profanas como religiosas ${ }^{30}$. En el cancionero mexicano popular contemporáneo sucede lo mismo, un motivo erótico como el alba también aparece en las canciones de tema religioso. Sobre todo en el primero de los ejemplos siguientes es claro que hay una supervivencia textual (vid supra); mientras que en los otros existe una supervivencia temática. En tanto que el primero es una oración para recibir al día, el segundo y el tercero hacen clara alusión al nacimiento de Cristo y en el último se puede ver el motivo del ave mensajera:

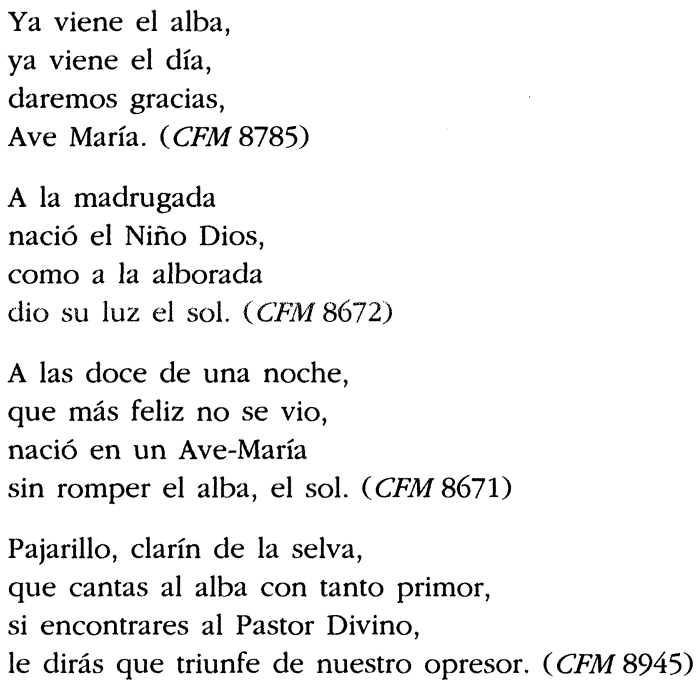

Algunos motivos literarios, debido al uso constante, pierden su significado y se convierten en frases formulaicas que sirven como versos introductorios para coplas de carácter sentencioso e incluso satírico. A veces se incluyen para completar una quintilla (vid supra la copla núm. 2801). En el cancionero popular mexicano, este fenómeno ocurre en coplas que evocan el amanecer. Aquí ya no hay reminiscencias de que esta sea la hora del encuentro amoroso, sino simplemente se ubica temporalmente la acción:

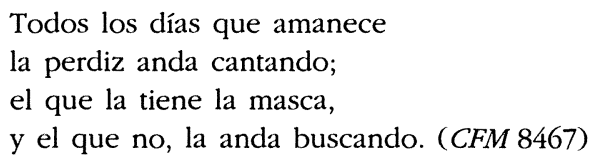

30 Veánse Bruce WARDROPPER, Historia de la poesía lírica a lo divino en la Cristiandad occidental (Madrid: Revista de Occidente, 1958), p. 153; José María ALín, op. cit., pp. 30-37. 
Todos los días que amanece

le pido a mi Dios eterno

que se muera un cabrón rico,

pa que se vaya al infierno. (CFM 9468)

Hasta aquí hemos visto cómo un motivo arcaico de carácter universal que aparece en la antigua lírica popular se preserva en la poesía popular contemporánea mexicana. En ella existen rasgos arcaizantes como el canto de las pájaros" o "cortar flores a la madrugada". También se puede señalar que en la mayoría de las coplas tanto el motivo del alba como aquelíos asociados a él preservan el significado erótico.

Por otra parte, se pueden señalar algunos rasgos diferenciadores entre los dos cancioneros. De acuerdo al punto de vista de los textos, en el cancionero mexicano la voz femenina ha disminuido y cambiado. Por el contrario, la voz masculina ha ampliado su espacio; sin embargo, el lenguaje directo de algunos textos, casi idéntico al de la voz femenina, sugiere que existe una influencia de la segunda sobre la primera.

Entre las innovaciones en la poesía popular mexicana, se encuentra el amanecer erótico utilizado como término comparativo de la belleza de la amada y combinado con el ancestral motivo de cortar flores, como en la imagen "Blanca rosa de Castilla / cortada al amanecer".

\section{ESTRUCTURAS: ¿TRADICIÓN O NOVEDAD?}

Las similitudes y diferencias entre la lírica hispánica tradicional antigua y la mexicana contemporánea ocurren también en las estructuras estróficas y silábicas. La convivencia estrecha entre la lírica popular antigua y la lírica culta contemporánea de los siglos XVI al XVII trajo como consecuencia un estilo diferente donde se regularizan las estrofas y la métrica, dando por resultado el predominio de la cuarteta octosilábica con rimas romances y la seguidilla ${ }^{31}$. Este nuevo estilo se manifiesta en las coplas de la lírica popular actual iberoamericana. Veamos este proceso en las coplas actuales mexicanas.

\subsection{Métrica y versificación}

En cuanto a las estrofas, en la antigua lírica tradicional predominan las estrofas de dos y tres versos, además de la versificación irregular. Por

31 Margit FRENK, Entre Folklore y literatura, p. 38. 
ejemplo los dísticos monorrimos, en este caso con versos heptasílabo y pentasílabo alternante:

\section{Ya viene el alva, niña,} ya viene el día. (C 1080)

Este dístico ha sobrevivido casi exactamente en la lírica tradicional mexicana, pero extendido hasta las dimensiones de una cuarteta que ha regularizado los versos en pentasílabos y preserva la rima en ía en los versos pares. Los dos últimos indican el carácter religioso del cantar:

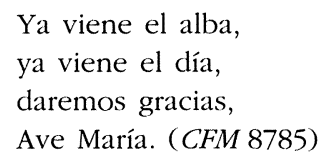

A diferencia de la antigua lírica, las estrofas en el cancionero popular mexicano tienden a extenderse incluso hasta quintillas o sextillas. Según su contenido conceptual, se puede decir que una estrofa - ya sea copla, quintilla o sextilla - puede ser unimembre, bimembre o trimembre o cada verso de la copla contener una idea independiente. Las sextillas pueden verse como una cuarteta a la que se le ha agregado un dístico ${ }^{32}$ o como cuartetas entrelazadas que comparten dos versos ${ }^{33}$. Veamos en los siguientes cantares ejemplos de una quintilla unimembre y de una sextilla trimembre:

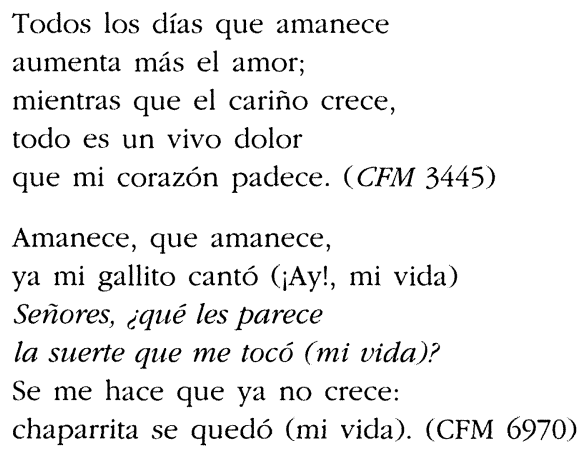

En el último ejemplo las cursivas marcan los versos compartidos por las supuestas dos cuartetas entrelazadas que conforman la sextilla. La com-

\footnotetext{
32 Margit FRENK, CFM, xxiv.

33 Raúl Dorra, Entre la voz y la letra (México: Plaza y Valdés; Benemérita Universidad Autónoma de Puebla, 1997), p. 53.
} 
binación de las rimas en ambas estrofas es igual: consonante "ece" en los pares y asonante en "Ó" en los impares. El frecuente uso de rimas consonantes y de la rima de los versos pares e impares entre sí, distingue a estas composiciones de los antiguos estribillos hispánicos.

\subsection{La repetición}

Uno de los rasgos estilísticos más comunes del poema oral es la repetición a nivel léxico sintáctico e incluso estrófico. Un repaso de los recursos en este pequeño corpus muestra la riqueza de combinaciones que ofrece la lírica. Se observa la existencia de la repetición semántica de unidad menor en los dos primeros versos ${ }^{34}$ :

$$
\begin{aligned}
& \text { Campirana, campirana, } \\
& \text { campirana, campiranita, }
\end{aligned}
$$

Otras veces la repetición de la palabra se extiende a tres versos, es decir, existe una combinación de repetición textual total en un verso y de anáfora que es producida por la enumeración:

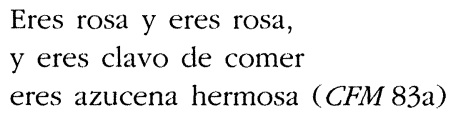

La repetición de la misma palabra en dos versos puede combinarse con el paralelismo:

Eres mi prenda querida, eres todo mi querer

El paralelismo ocurre también a nivel sintáctico en ciertas coplas bimembres. Los primeros dos versos son una afirmación y los últimos explican lo anteriormente dicho en la segunda parte de la copla:

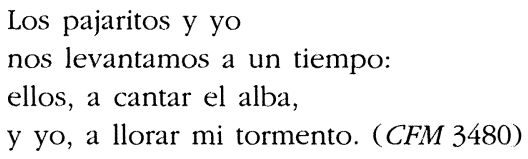

34 En el estudio de los recursos estilísticos entre el romancero y la lírica popular moderna Mercedes DíAz ROIG, El Romancero y la lírica popular moderna (México: El Colegio de México, 1976), distingue como las tres figuras más destacadas en la poesía popular: la repetición, la antítesis y la enumeración. 
Como hemos visto, los recursos estilísticos del cancionero mexicano son similares a aquellos del cancionero antiguo, ya que se basa en la repetición, enumeración y paralelismo, elementos esenciales del estilo popular.

\section{CONCLUSIONES}

Después de un breve recorrido en el cancionero mexicano hemos visto que existen motivos universales como el alba erótica, lo que indica que éste no es un fenómeno literario aislado, sino que se vincula con otras tradiciones como la medieval hispánica.

El estudio temático de las coplas mexicanas revela la preservación del erotismo de motivos como el alba y algunos de los que gravitan alrededor de él, como cortar flores y el canto de los pájaros.

En cuanto a las divergencias, el cancionero mexicano incorpora nuevos elementos que distinguen e identifican a este cancionero frente al cancionero antiguo, como fundir los dos motivos arcaicos de la flor cortada y el amanecer para describir la belleza de la amada. Además de que el alba aparece mezclada con "las mañanitas" o las despedidas antes de partir al trabajo.

En cuanto al punto de vista, se ha observado que existen canciones de voz masculina en el cancionero mexicano donde se trasluce la existencia de un casi travestismo de la voz, ya que a pesar de tener marca textual masculina, el modo de expresión es similar al de la voz femenina de los antiguos estribillos.

El análisis estructural muestra algo similar. Por un lado las albas españolas antiguas y las mexicanas modernas comparten recursos estilísticos tales como el paralelismo, la enumeración y la repetición. Pero, por otro, el cancionero mexicano innova en la estructura estrófica, como muestran la abundancia de quintillas y sextillas.

Se desprende de este primer análisis que el cancionero mexicano popular no sólo se distingue del cancionero medieval en sus aspectos temáticos, sino también en los formales. Ello demuestra que la tradición oral no sólo es un repertorio fijo conservado a través del tiempo, sino que también es innovadora. 
Los antecedentes de algunos motivos eróticos de la poesía tradicional mexicana contemporánea en español se pueden rastrear hasta las canciones populares hispánicas de la Edad Media. Sin embargo, aún hoy no se han estudiado en profundidad las relaciones y desencuentros entre la canción popular mexicana y la antigua canción peninsular; por ello, este trabajo se propone como un primer análisis. El estudio resalta la originalidad de las coplas mexicanas a través de un estudio comparativo del motivo del alba.

The roots of some erotic motifs in Mexican traditional songs in Spanish could be traced to the Medieval Popular Hispanic songs, as has been said by scholars. But, until now, nobody has studied in depth the relationship and diversity between the Mexican cancionero and old Spanish songs. In this article I shall analize the preservation of the Dawn motif, and all those associated with it, in Mexican Contemporary Songs and variation. 